\title{
GENERATION OF TRIP FORECASTING MODEL FOR SARDAR PATEL RING ROAD: A CASE STUDY OF AHMEDABAD CITY
}

\author{
Pravek Dwivedi ${ }^{1}$, Rajesh Gujar ${ }^{2}$, Dharmik Modha ${ }^{3}$, Monil Bhatt ${ }^{4}$ \\ ${ }^{1}$ Undergraduate Student; Department of Civil Engineering, School of technology, PanditDeendayal Petroleum \\ University, Gujarat, India \\ ${ }^{2}$ Assistant Professor, Department of Civil Engineering, School of Technology, PanditDeendayal Petroleum University, \\ Gujarat, India \\ ${ }^{3}$ Undergraduate Student; Department of Civil Engineering, School of technology, PanditDeendayal Petroleum \\ University, Gujarat, India \\ ${ }^{4}$ Undergraduate Student; Department of Civil Engineering, School of technology, PanditDeendayal Petroleum \\ University, Gujarat, India
}

\begin{abstract}
With about 5.6 Million people, Ahmedabad is the biggest town of Gujarat state in India. Ahmedabad is growing at an exponential rate. As a result, the demand for infrastructure and transportation needs is also increasing. To design any of the transportation facility, scope for future demand is to be incorporated. Traffic is a dynamic phenomenon. Modelling of traffic is quite difficult and arduous task. This study involves the study of traffic in various areas of Ahmedabad within Sardar Patel Ring Road which covers major part of Ahmedabad city with an area of $484 \mathrm{~km}^{2}$. This Research project involves modelling of traffic which yields the number of trips generated in future. Out of around 250 houses visited, 130 agreed to provide relevant data for the project and hence 130 Data samples were collected from households by door to door survey. Mathematical modelling of data collected by door to door survey of households within the study area was done. Regression and Co-relation analysis were carried out using 4 parameters. Family size and composition and number of vehicles of different types i.e. two wheelers and four wheelers were taken as parameters for trip generation.It was observed that the most impactful factor for trip generation is the number of two wheelers with correlation coefficient of (+0.97) whereas the least impactful factor was the number of females in a household with correlation coefficient of (-0.05). The parameters chosen for study are relevant in any area of Ahmedabad and hence this model can be used anywhere to estimate the number of trips.
\end{abstract}

Keywords: - Sardar Patel Ring Road; Door to Door Survey; Regression and Co-relation analysis; Trip Forecasting Model

\section{INTRODUCTION}

Ahmedabad is the largest city of Gujarat. It was ranked third in Forbes's list of fastest growing cities of the decade in the year 2010. As a ramification, traffic is increasing at higher and higher rates. Traffic is increasing at one end and on the other end, road, public transport facilities, routes etc. are stagnant. As a result, several facilities such as roads, public transport facilities etc. need to accommodate more number of users then their design capacity. This leads to failure and cause of unwanted and deleterious phenomenon such as accidents, congestion, and traffic jams etc. $44 \%$ of the accidents in Ahmedabad were caused due to inappropriate infrastructure facilities such as inadequate width of pathway, medians, footpaths etc. To avoid this, forecast of trips to be generated in future must be done and infrastructure must be developed keeping in mind future demands.

Trip generation is a term used in transportation planning which deals with calculation of number of trips generated. Main aim of studying trip generation is to study the trips generated, reason for the same and to know origin and destination of trip[1]. Study of origin and destination is one of the main factors to be considered for studying trip generation. Origin can be defined as a point or location from where the trip starts. It can be home, place of work, recreational center or any other place. Destination is defined as a point or location where trip ends. It can be office, temple, garden etc. As a paradigm, if a person trips from his home to his place of work, his home is considered as origin and his place of work is termed as destination. Trips can be classified into two types i.e. home based trips and non-home based trips[2]. Home based trips are considered as trips whose either end is home. If origin or destination of a trip is home, it is called home-based trip. Non-home based trips can be defined as trips whose neither end is home. In a trip if, neither origin nor destination is home, it can be termed as non-home based trip. Trips are usually defined or classified on the basis of its purpose. Trips are generated for various purposes such as work, school, business, attending social functions, recreational places such as garden, sports etc. Apart from these usual trips, there are some trips which 
occur rarely but surely occur. These trips include trips generated by a person visiting temple, mosque, church etc.
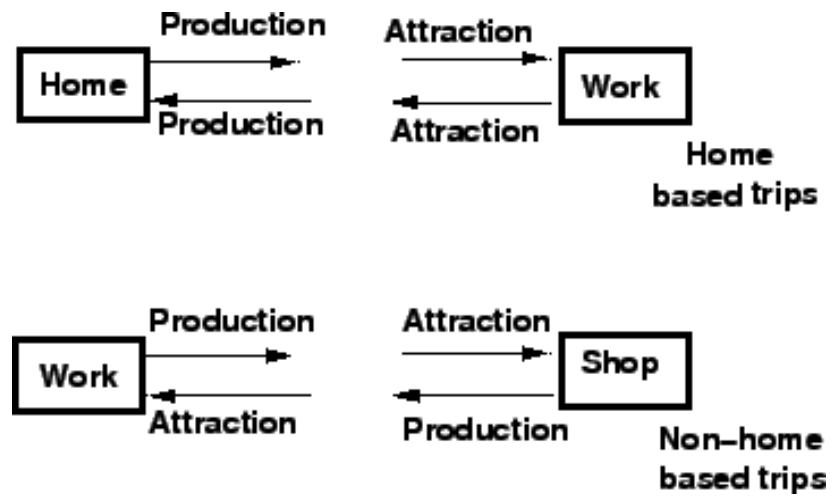

Fig 1: Classification of trips.

Many factors affect trip generation and the way trips are conducted. Major factors affecting trips are as follows[1]-

- Income - If total income of the household is high, more vehicle will be owned by them. As a result, more trips will be generated from that household.

- Family Size - Family size highly matters number of trips generated. If there are more members in family, more trips are likely to generate from that household.

- Family Composition and Structure - Family structure affects trips generated and more specifically the zones in which trips are diverted. If more elderly member are there in a family, more trips in areas of gardens, temples, religious places etc. are generated. Whereas if more children are there, trips in areas of schools, tuitions, libraries, parks etc. are more.

- Working Members in Household - If the number of working members in a household is more, trips generated from that house will be more.

- Other Factors - There are other factors which implicitly or explicitly affect trip generation such as accessibility to public transport, residential density, value of land etc.

In Ahmedabad, as mentioned earlier traffic is increasing exponentially. Trips are generated from almost all the areas of Ahmedabad. At least one trip is generated from each household daily. Usually trips are generated from residential areas of Ahmedabad such as Satellite, Bopal, Gota, Thaltej, Chandkheda etc. These trips are diverted to destination which is usually a commercial and industrial zone such as Naroda, Vatva, Odhav, GIDC etc.

\section{LITERATURE REVIEW AND STUDY AREA}

Several models have been suggested for forecasting trips. Each model has different approaches and different parameters whereas the final aim is similar i.e. to predict the number of trips in future. A hybrid model developed using logistic regression and wavelet transformation to detect traffic incidents. Logistic regression on raw data resulted in a maximum detection rate of $95.4 \%$ at the cost of $14.5 \%$ false alarm rate. Whereas the hybrid model achieved a maximum detection of $98.78 \%$ at the expense of $6.5 \%$ false alarm rate[3]. By developing the local linear regression model for short term traffic forecasting, it was found that it has consistently better performance than the nearest neighborhood and the kernel smoothing method[4]. In another research it was discovered that current urban land use and transport interaction (LUTI) models perform well in practical applications with regard to the urban policy and infrastructure planning[5]. In a review, some issues related to the use of simulation in transportation analysis were discussed. Potential pitfalls were identified and discussed[6]. Various existing challenges were reviewed in review paper and suggestions for future work were given[7]. In another article, a new approach was introduced to short term daily traffic flow prediction based on artificial neural networks. Among the family of neural networks, Multi-layer perceptron (MLP), Radial Basis Function (RBF), neural networks and wavenets had been selected as the three best candidates for performing the traffic flow prediction[8]. To know about recent trends, a paper titled Short-term Traffic Forecasting: Overview of Objectives and methods was studied. It discusses different models developed for traffic forecasting in past two decades[9].

Study area to be selected needs to meet certain criteria. Keeping in mind various parameters, study area was selected as Sardar Patel Ring road. It covers major part of Ahmedabad city. In fact it encircles complete city.

\section{RESEARCH METHODOLOGY}

Basic aim of this project was to project number of trips generated in future in concerned study area i.e. Sardar Patel Ring Road. To forecast traffic, mathematical modelling was adopted. Mathematical modelling involved Regression and correlation analysis. Using Regression analysis, an equation was generated whose variables were the traffic parameters. Four parameters were selected to perform mathematical analysis. These parameters are-

1. Number of two-wheelers

2. Number of four-wheelers

3. Number of males in a family

4. Number of females in a family

To generate authentic and reliable data, door to door survey was carried out. Many households were visited and a questionnaire form was filled as per the informationreceived from residents. After the data was generated, its mathematical modelling was done. Mathematical modelling involved Regression analysis which was used to generate equation and Correlation analysis which was used to knowthe impact ofdifferent parameters on number of trips generated daily.

The results generated were represented graphically to get a broader view. Using the model generated, trips generated in future were calculated.

Sample data sheet obtained from survey is as follows- 
Table 1: Sample Data Sheet

\begin{tabular}{|c|c|c|c|c|c|c|c|}
\hline $\begin{array}{l}\text { Sr. } \\
\text { No. }\end{array}$ & $\begin{array}{l}\text { Address } \\
\text { (Origin) }\end{array}$ & $\begin{array}{l}\text { No. of } \\
\text { males }\end{array}$ & $\begin{array}{l}\text { No. of } \\
\text { females }\end{array}$ & $\begin{array}{l}\text { No. of } 2 \\
\text { Wheelers }\end{array}$ & $\begin{array}{l}\text { No. of } 4 \\
\text { Wheelers }\end{array}$ & $\begin{array}{l}\text { Destination } \\
\text { Area (Regular } \\
\text { basis) }\end{array}$ & $\begin{array}{l}\text { Usual } \\
\text { Time of } \\
\text { trip }\end{array}$ \\
\hline 1 & $\begin{array}{ll}\begin{array}{l}\text { Samukta } \\
\text { (Ranip) }\end{array} & \text { appt. } \\
\end{array}$ & 2 & 2 & 1 & 1 & Shreeji road & $\begin{array}{l}9.00 \mathrm{am}- \\
7.00 \mathrm{pm}\end{array}$ \\
\hline 2 & $\begin{array}{l}\text { 35, Nakum } \\
\text { Society, } \\
\text { (Chandkheda) }\end{array}$ & 3 & 2 & 2 & 1 & Navoday & $\begin{array}{l}9.30 \mathrm{am}- \\
8.00 \mathrm{pm}\end{array}$ \\
\hline 3 & $\begin{array}{l}15 / 18 \\
\text { Shivamappts. } \\
\text { (Ashram Road) }\end{array}$ & 2 & 2 & 2 & 1 & C.G. Road & $\begin{array}{l}10.00 \mathrm{am}- \\
5.00 \mathrm{pm}\end{array}$ \\
\hline 4 & $\begin{array}{l}\text { Sahara Society } \\
\text { (Ghatlodia) }\end{array}$ & 3 & 1 & 3 & 1 & Satellite & $\begin{array}{l}9.00 \mathrm{am}- \\
6.00 \mathrm{pm} \\
\end{array}$ \\
\hline 5 & $\begin{array}{l}4, \quad \text { Chaitanya } \\
\text { Society } \\
\text { (Vastrapur) }\end{array}$ & 4 & 2 & 2 & 1 & S.G. Highway & $\begin{array}{l}10.00 \mathrm{am}- \\
4.00 \mathrm{pm}\end{array}$ \\
\hline 6 & $\begin{array}{l}\text { E-102 Shreeji } \\
\text { tower } \\
\text { (Sashtrinagar) }\end{array}$ & 2 & 2 & 2 & 0 & Prahladnagar & $\begin{array}{l}9.00 \mathrm{am}- \\
6.00 \mathrm{pm}\end{array}$ \\
\hline 7 & $\begin{array}{l}\text { A-202 Arjun } \\
\text { Appts. } \\
\text { (Pragatinagar) } \\
\end{array}$ & 1 & 0 & 1 & 0 & Navrangpura & $\begin{array}{l}9.00 \mathrm{am}- \\
4.30 \mathrm{pm}\end{array}$ \\
\hline
\end{tabular}

\section{MATHEMATICAL MODELLING}

Considering different parameters, first of all their individual correlation co-efficient were found out. Later on, first individual parameters were linked with number of trips generated and later on all the four equations were clubbed together to form a master equation.

\subsection{Number of Trips and Number of Two Wheelers}

Equation generated is as follows -

Correlation coefficient - 0.96246118

Regression model -

Trips per Day Vs. Number of 2 Wheelers

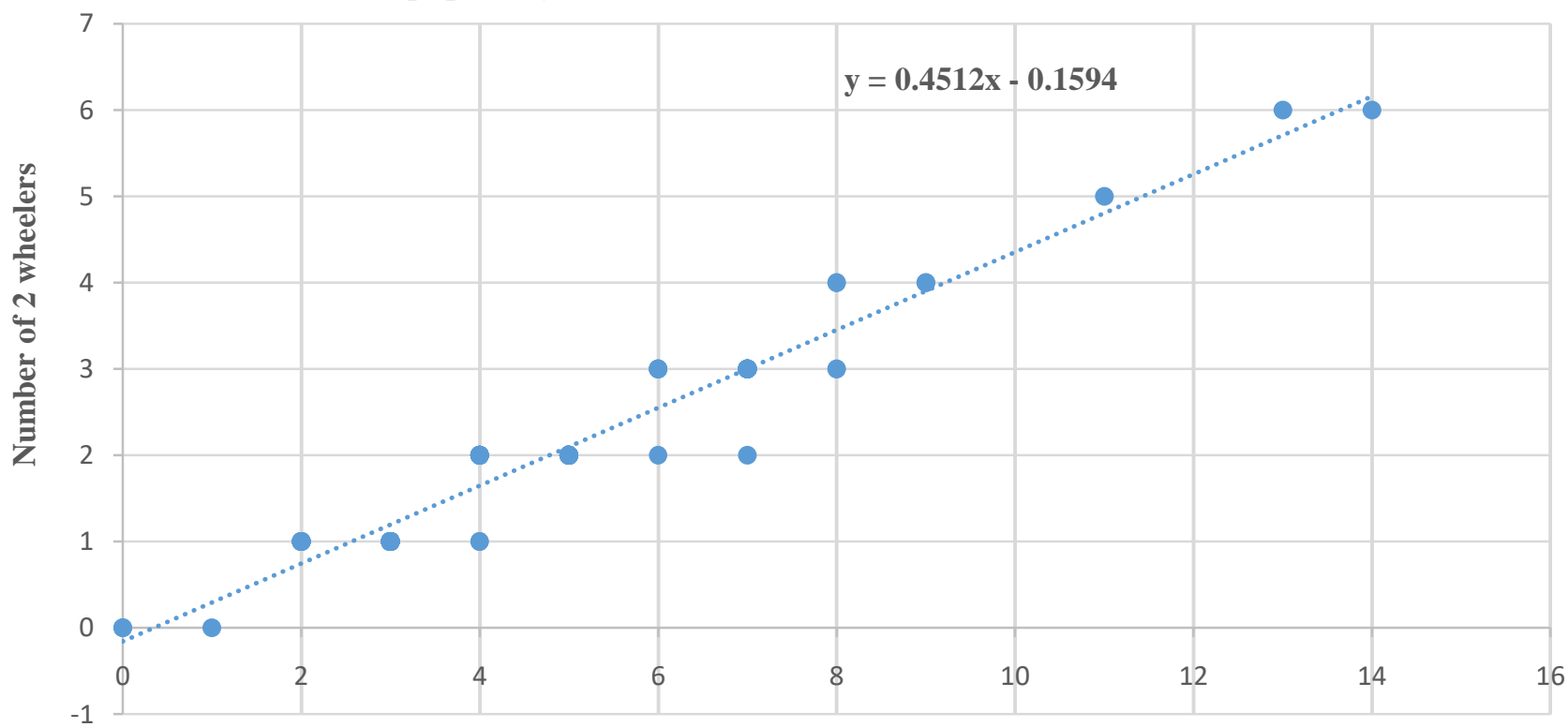

Trips per day

Fig 2: Regression model 01. 


\subsection{Number of Trips and Number of Four Wheelers}

Equation generated is as follows

Correlation coefficient -0.310377869

Regression model -

Trips per day Vs. Number of 4 wheelers

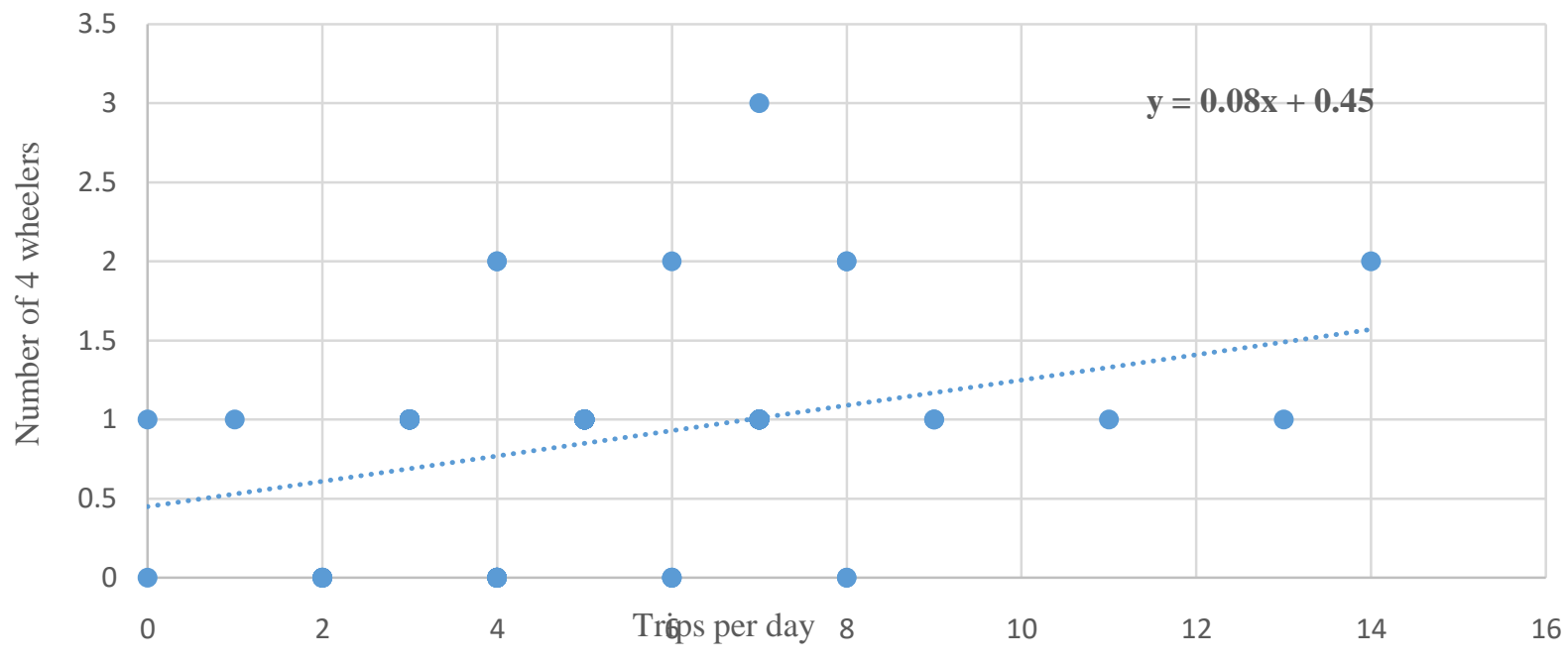

Fig 3: Regression model 02.

\subsection{Number of Males in a Family}

Equation generated is as follows-

Correlation coefficient -0.125962838

Regression model -

Trips per day Vs. Number of males

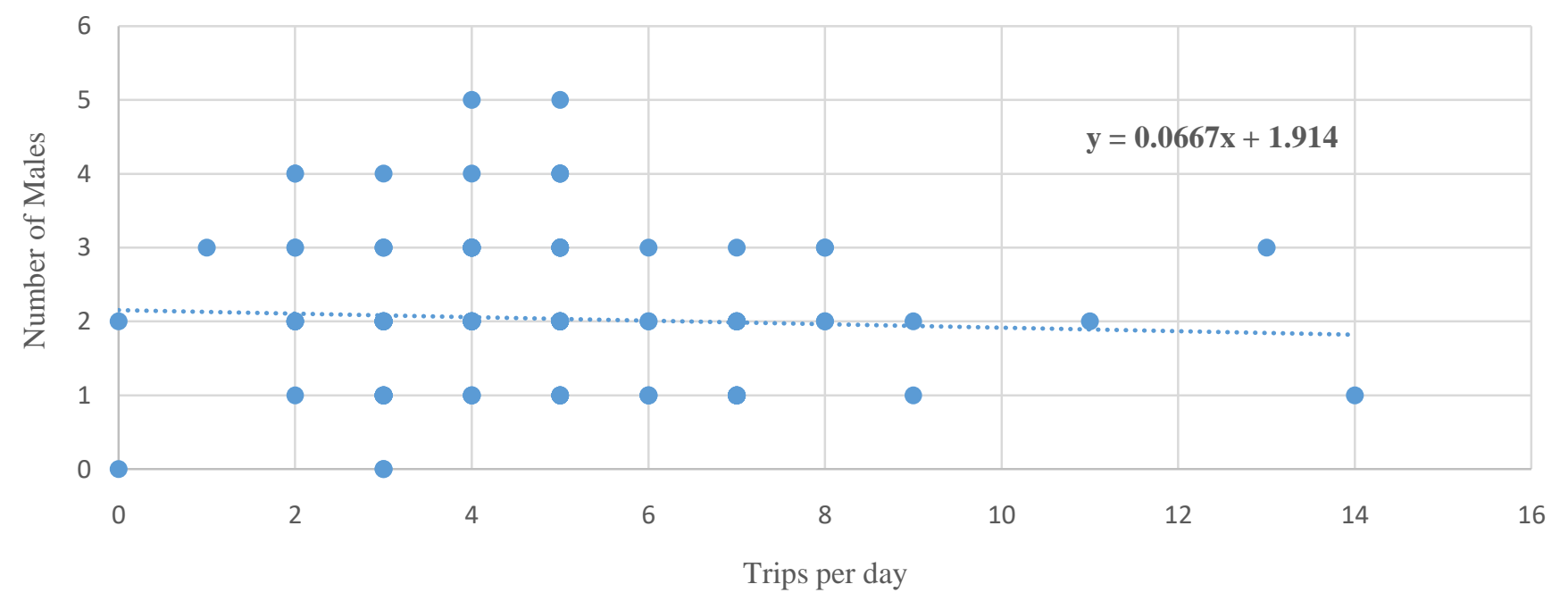

Fig 4: Regression model 03. 


\subsection{Number of Females in a Family}

Equation generated is as follows -

Correlation coefficient $-(-0.050518958)$

Regression model -

Trips per day Vs. Number of Females

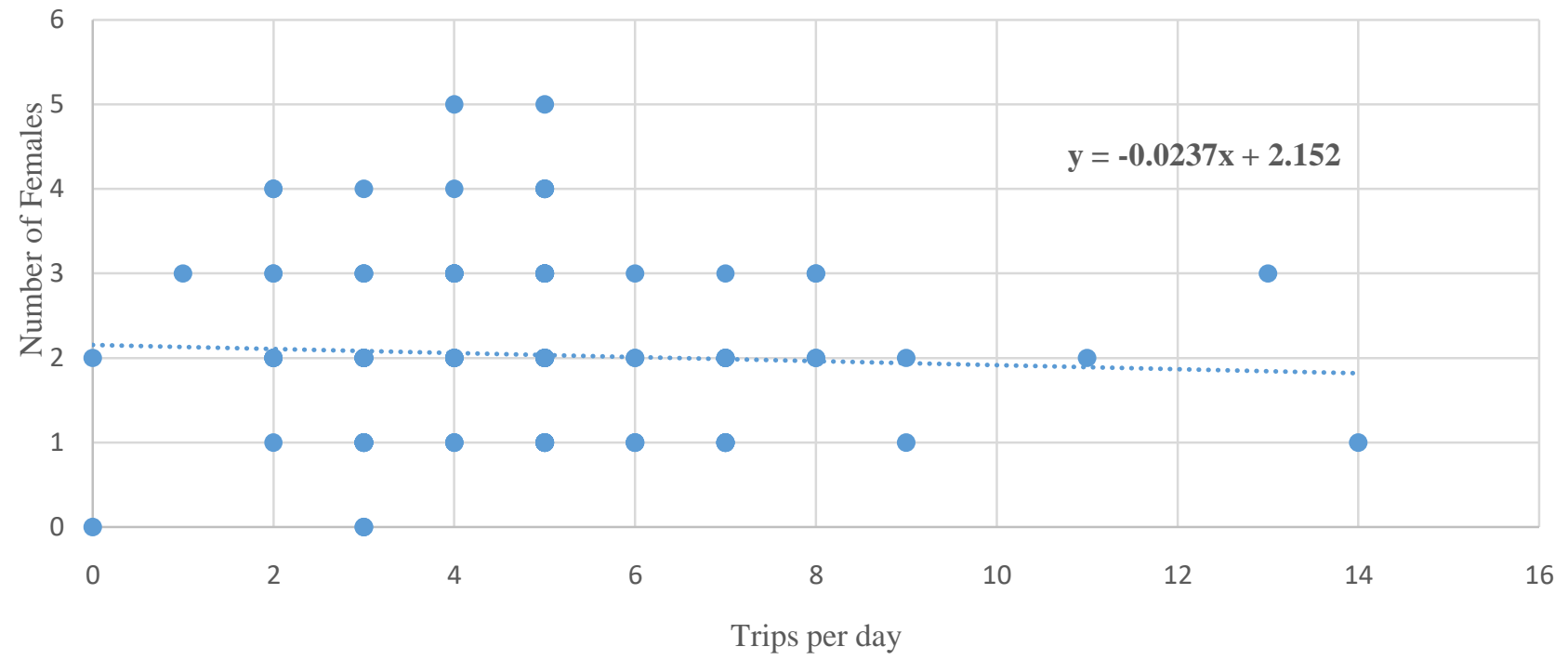

Fig 5: Regression model 04.

\section{RESULTS AND DISCUSSION}

Mathematical model has been developed as shown above. Based on Least square fitting i.e. regression model, nature of dependence between two variables can be interpreted.
Correlation coefficients are found out between number of trips per day and all the four parameters. Based on the values of Correlation coefficients, following can be interpreted -

Table 2: Co-relation Values

\begin{tabular}{|l|l|l|l|}
\hline $\begin{array}{l}\text { Sr. } \\
\text { No. }\end{array}$ & $\begin{array}{l}\text { Correlation coefficient between } \\
\text { Number of trips per day and factors: }\end{array}$ & $\begin{array}{l}\text { Value of Correlation } \\
\text { coefficient- }\end{array}$ & Interpretation \\
\hline 1. & Number of two wheelers in a household & 0.96 & Very Strong positive correlation exists \\
\hline 2. & Number of four wheelers in a household & 0.31 & Weak positive correlation exists \\
\hline 3. & Number of males in a household & 0.13 & Very weak positive correlation exists \\
\hline 4. & Number of females in a household & $\mathbf{( - 0 . 0 5 )}$ & Very weak negative correlation exists \\
\hline
\end{tabular}

Looking at the data presented above, it can be seen that number of trips generated per day will be highly affected by number of then wheelers followed by number of four wheelers and number of male. Surprisingly, negative correlation exists between number of females in a household and number of trips per day.

Summing up all the parameters, master equation generated is as follows -

$$
\mathrm{T}=0.123 \mathrm{~W}+0.02 \mathrm{X}+0.017 \mathrm{Y}-0.006 \mathrm{Z}+1.1
$$

Considering $(+10 \%)$ error correction, the values will increase by $10 \%$ in above equation. Hence the final equation is as follows -

$$
T=0.135 W+0.022 X+0.019 Y-0.007 Z+1.21
$$

In this equation,

- $\mathrm{T}=$ Number of trips generated per day per household

- $\mathrm{W}=$ Number of two wheelers in a household

- $X=$ Number of four wheelers in a household

- $\quad Y=$ Number of male members in a family

- $\quad \mathrm{Z}=$ Number of female members in a family 
Hence to know the number of trips in a year per household, the equation needs to be multiplied by 365 . Hence the equation is as follows -

$$
\mathrm{T}=49.275 \mathrm{~W}+\mathbf{8 . 0 3 X}+6.935 \mathrm{Y}-2.555 \mathrm{Z}+441.65
$$

In this case, number of trips generated will be for a complete year. If this model is to be used to calculate number of trips generated in a particular town or city throughout a year, above equation must be multiplied by number of households in that town or city.

\section{REFERENCES}

[1] L. Kadiyali, Traffic Engineering and Transport Planning, Delhi: Khanna Publishers, 2011.

[2] P. P. C.S. Papacostas, Transportation engineering and planning, Pearson, 2015.

[3] P. K. E. R. Shaurya Agarwal, "A hybrid model using Logistic regresssion and wavelet transformation to detect traffic incidents," IATSS Research, 2016.

[4] H. X. L. H. X. B. R. Hongyu Sun, "Short term traffic forecasting using the Local Linear Regression model," in TRB Annual meeting, Irvine, 2002.

[5] H. N. K. N. K. D. Masanobu Kii, "Transportation and spatial development: An overview and a future direction," Transport Policy, 2016.

[6] M. Bierlaire, "Simulation and optimization: A short review," Transportation research, 2015.

[7] M. G. K. J. C. G. Eleni I. Vlahohianni, "Short term traffic forecasting: Where we are and where we're going," Transportation Research, 2014.

[8] B. M. Javed Abdi, "Application of temporal difference learning rules in short-term traffic flow prediction," Expert Systems, 2015.

[9] J. C. G. M. G. K. Eleni I. Vlahogianni, "Short term traffic forecasting: Overview of objectives and methods," Transportation Reviews, 2016.

\section{BIOGRAPHIES}

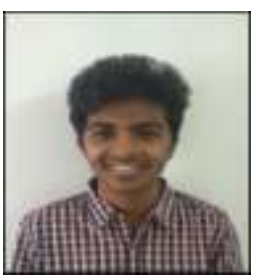

Pravek Dwivedi is an Undergraduate student of Civil Engineering at PanditDeendayal Petroleum University. He will complete his Bachelor's degree in May-2018. He has done 4 research projects and 2 internships. He has published a paper in ASCE Conference proceedings in ASCE India Conference-2017. Pravek ranks amongst top $5 \%$ of his batch.

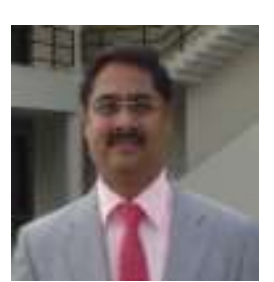

Dr. Rajesh Gujar is working as an Assistant Professor at PanditDeendayal Petroleum University, Gandhinagar. Dr. Rajesh Gujar has earned his doctoral degree $(\mathrm{PhD})$ in Transportation Engineering from SVNIT (SardarVallabhbhai National Institute of Technology, Surat. He has visited various countries like Singapore, Malaysia, Srilanka, Thailand and presented his
research.He has also been nominated to take summer course on Transportation Engineering and also to accompany with School of Technology students for International Exposure Program at Lamar University, Beaumont, Texas, USA. He has published 4 papers in International Journals \& 8 papers in International \& National Conferences.

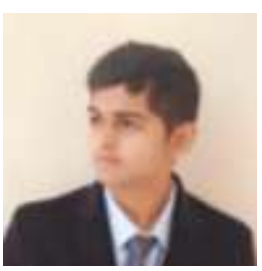

DharmikModha is an Undergraduate Student of Civil Engineering at PanditDeendayal Petroleum University. He will complete his Bachelor's degree in May-2018.

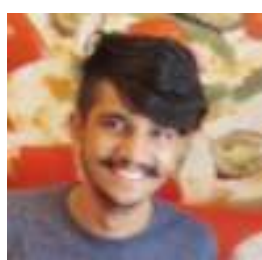

Monil Bhatt is an Undergraduate Student of Civil Engineering at PanditDeendayal Petroleum University. He will complete his Bachelor's degree in May-2018. 